\title{
Impaired autonomic control of heart interval changes to Valsalva manoeuvre in Chagas' disease without overt manifestation
}

\author{
Luiz Fernando Junqueira Jr. ${ }^{\text {a,b,* }}$, Joaquim Domingos Soares ${ }^{\text {a,b }}$ \\ ${ }^{a}$ Cardiovascular Laboratory, Clinical Medicine Area, Faculty of Medicine, University of Brasilia, Brasilia, DF, 70910-900, Brazil \\ ${ }^{\mathrm{b}}$ Division of Cardiology, Brasilia University Hospital, Brasilia, Brazil
}

Received 9 August 2001; received in revised form 10 December 2001; accepted 14 January 2002

\begin{abstract}
Background: In the apparent indeterminate form of Chagas' disease, which lacks any overt clinical, electrocardiographic, and radiological manifestations of organ damage, lesions of the intrinsic autonomic innervation of heart are not striking features and evidences for cardiac autonomic dysfunction are elusive and conflicting. Objective: To evaluate the cardiac autonomic modulation based on Valsalva manoeuvreassociated heart interval variation in Chagas' disease subjects with apparent indeterminate form. Subjects and methods: We examined 36 outpatient volunteers aged 15-51 years old (median: 36.5), in comparison with 52 healthy control individuals aged 17-49 years old (median: 29) $(p<0.001)$. Each subject sequentially performed in the supine position three to four manoeuvres at an intra-oral pressure of 40 $\mathrm{mm} \mathrm{Hg}$ during $20 \mathrm{~s}$, under continuous DII lead electrocardiographic registration, and rate- and time-dependent indices of Valsalva manoeuvre-associated $\mathrm{R}-\mathrm{R}$ interval variation were obtained. The $t$-test or the Mann-Whitney test was employed to compare the data between the groups. Results: No correlation was found between every index and age for the control group $(p=0.39-0.71)$. The chagasic group presented similar basal to phase IV median increment (relative bradycardia) $(23.7 \%$ vs. $22.7 \%$; $p=0.63)$ and smaller basal to phase III median decrement of $\mathrm{R}-\mathrm{R}$ interval (relative tachycardia) $(-31.7 \% \mathrm{vs} .-35 \% ; p=0.02)$ in comparison to the control group, respectively. The median Valsalva ratio showed a tendency for reduction in chagasics $(1.78$ vs. $1.90 ; p=0.08)$. Prolonged median time (14.2 vs. $10.3 \mathrm{~s}$; $p<0.001)$ and slowed median velocity $(5.1 \% / \mathrm{s}$ vs. $8.9 \% / \mathrm{s} ; p<0.001)$ of the phases III-IV bradycardia were also observed in chagasic group. The majority $(58.3 \%)$ of the chagasics presented exclusively at least one depressed, and $8.3 \%$ presented at least one enhanced index of rateand/or time-dependent heart interval responses beyond the 25 th or 75 th control percentiles, and $27.8 \%$ presented at least one depressed and other enhanced index, while $5.6 \%$ showed all indices within the control interquartile range. All the indices outside the 25 th or 75 th control percentiles were noted in $13.9 \%$ of chagasics. Conclusion: Chagas' disease subjects without overt manifestations presented variable and subtle depression and less frequent enhancement or normality of the rate- and time-dependent tachycardia and bradycardia reflex responses related to Valsalva manoeuvre, which demonstrates distinct patterns of finely disturbed cardiac sinus parasympathetic and sympathetic modulation, probably due to inflammatory or autoimmunological damage of intrinsic innervation and/or to autoantibodies-induced derangement in neurotransmitter receptors. (C) 2002 Elsevier Science B.V. All rights reserved.
\end{abstract}

Keywords: Chagas' indeterminate disease; Valsalva manoeuvre-associated tachycardia and bradycardia; Heart interval variation; Chagas' heart autonomic dysfunction

\section{Introduction}

Chagas' disease is a serious endemic infection in South and Central America affecting 16-18 million people (WHO, 1991) under different chronic clinical forms namely, indeterminate, isolated cardiac or digestive, and cardiacdigestive combined. The indeterminate form is the most

\footnotetext{
* Corresponding author. Cardiovascular Laboratory, Clinical Medicine Area, Faculty of Medicine, University of Brasilia, Brasilia, DF, 70910-900, Brazil. Tel.: +55-61-307-2274; fax: +55-61-273-3907.

E-mail address: 1fjjnq@embratel.net.br (L.F. Junqueira Jr.).
}

frequent, representing around $50 \%$ of the chronically infected subjects and usually has a long-lasting benign clinical course. It is defined by the lack of overt expression of organ involvement traduced by the absence of clinical manifestations, a normal conventional electrocardiogram and radiological exploration of the heart and the upper and lower digestive tract, in the presence of positive serological reaction for the infection (Dias, 1989; Macêdo, 1999). The forms with overt organ damage, which develops up to 30 years after the acute phase of infection affecting 23 million people (WHO, 1991; Macêdo, 1999), are characterized by peculiar clinical, electrocardiographic, echocar- 
diographic, and/or radiological evidences of cardiac or digestive involvement in the presence of positive serology. It is estimated that $2-5 \%$ of cases with indeterminate form evolve toward the overt organic forms each year (Dias, 1989).

In the chronic-isolated or combined cardiac and digestive forms of Chagas' disease, a striking pathological feature is the involvement in variable degree of the autonomic intrinsic innervation of heart (Lopes and Tafuri, 1983; Oliveira, 1985). The human and experimental indeterminate forms present less conspicuous lesions of cardiac intrinsic innervation, which are usually represented by discrete to moderate focal or zonal chronic neuroganglionitis (Lopes and Tafuri, 1983; Andrade, 1984; Oliveira, 1985; Chapadeiro et al., 1991). Cardiac autonomic damage has also been observed in acute and chronic experimental Trypanosoma cruzi infection in mice (Tafuri, 1970; Souza et al., 1996), dogs (Andrade, 1984; Machado et al., 1998), rats (Chapadeiro et al., 1991; Junqueira et al., 1992), and hamsters (Chapadeiro et al., 1999) among other animal models.

Consequent to this autonomic pathological involvement, well-defined although variable primary cardiac parasympathetic dysfunction and less obvious but detectable sympathetic disturbance were repeatedly observed by means of different study methods in chagasics with the cardiac-isolated or combined clinical forms with or without heart failure (Marin-Neto et al., 1980; Amorim et al., 1982; Gallo et al., 1987; Junqueira, 1990; Marin-Neto, 1998). In the rat model of $T$. cruzi infection, cardiac parasympathetic disturbance could also be detected as depressed baroreflex bradycardia response (Junqueira et al., 1992).

Studies on the cardiac autonomic function in chagasics with the indeterminate form are scarce. Few observations employing different functional tests are apparently conflicting, some authors having noted autonomic dysfunction and others did not. Prolongation in the atrium-ventricular conduction at the electrocardiogram following pilocarpine administration (Macêdo et al., 1974), and deficient heart rate response to hyperventilation (Iosa et al., 1980) and tilting test (Palmero et al., 1980) were demonstrated. Depressed heart rate variability analysed in the frequencydomain during standing and handgrip exercise was shown, which suggests sympathetic and parasympathetic dysfunction (Guzzetti et al., 1991). In another study, respiratory sinus arrhythmia and heart rate variability in the timedomain and in return map were shown to be depressed, besides normal left ventricular function, demonstrating primary parasympathetic impairment (Ribeiro et al., 2001). On the other hand, evaluation of the heart rate changes in the Valsalva manoeuvre and in head-up tilt test, and of baroreflex sensitivity using the phenylephrine injection method, did not identify any autonomic disturbance (Marin-Neto et al., 1998). We are also unable to detect baroreflex sensitivity alteration in four Chagas' indeterminate disease cases (Junqueira et al., 1985).
Thus, aiming to clarify the question, we evaluate the cardiac sinus autonomic modulation based on previously described indices of Valsalva manoeuvre-associated heart interval variation (Junqueira, 1990) in subjects with apparent indeterminate form of Chagas' disease in comparison with healthy controls, which may contribute to the understanding of the pathophysiology of this important and intriguing condition.

\section{Subjects and methods}

\subsection{Subjects}

A group of 36 consecutively recruited outpatients (15 males and 21 females) aged 15-51 years with the apparent Chagas' indeterminate disease, living or not in rural endemic areas, was compared with a group of 52 healthy control subjects (39 males and 13 females) aged 17-49 years living in urban areas. The chagasic group presented median and quartiles values of age $(36.5,30-43.5$ years $)$ statistically greater $(p<0.001)$ than the control group $(29,24-34$ years). The diagnostic criteria of this form of Chagas' disease were based on the presence of two conventional positive serologic reactions for the disease (Guerreiro-Machado's complement fixation and indirect immunofluorescence), in the absence of any suspected clinical general and organ-specific manifestations, and in an undoubtedly normal conventional electrocardiogram. The questionable criterion of radiological screening of the upper and lower digestive tract for search of possible asymptomatic megaoesophagus or megacolon was not indiscriminately conducted in all the chagasics, considering the very low mean prevalence, around $2-3 \%$ of digestive involvement, and the ethical, practical, and economical restrictions imposed by that examination. Only those few with symptoms had radiological examination of the oesophagus and lower intestinal tract, which were normal. All the chagasic subjects had history of epidemiological exposure to the vector of the disease and were in excellent physical and mental conditions and not using any drugs.

The resting arterial pressure and heart rate assessed in the experimental session were within the normal range for all subjects, with no significant difference $(p>0.05)$ between the chagasic $(121 \pm 9 / 79 \pm 5 \mathrm{~mm} \mathrm{Hg} ; 908 \pm 104 \mathrm{~ms})$ and control groups $(116 \pm 8 / 78 \pm 4 \mathrm{~mm} \mathrm{Hg} ; 922 \pm 155 \mathrm{~ms})$. This investigation was performed under the universal principles for the research in human beings based in the Helsinki declaration, and all the individuals were informed about the study and gave full consent to participate.

\subsection{Valsalva manoeuvre protocol}

The chagasic and the control subjects participated in the Valsalva manoeuvre session in the middle of the morning coming from their routine activities. The experimental sessions were conducted in a quiet laboratory room at the 
ambient temperature of $20-24{ }^{\circ} \mathrm{C}$. Initially, each individual was instructed in the Valsalva manoeuvre and practiced it sometimes for training. In sequence, after sufficient time of resting, three to four spaced valid manoeuvres were done for each subject in the rest supine position by blowing with the closed glottis into the mouthpiece-tubing connected to an aneroid manometer in order to maintain a constant expiratory intra-oral pressure of $40 \mathrm{~mm} \mathrm{Hg}$ for $20 \mathrm{~s}$ according to standardized previous protocol (Manço et al., 1969; Eckberg, 1980; Junqueira, 1990; Marin-Neto et al., 1998). The Valsalva manoeuvre comprises four phases of baroreflex heart interval changes to arterial pressure modifications: (1) rapid inspiration and onset of the expiratory straining with a variably present evanescent bradycardia associated to a transient systolic arterial pressure rise (phase I); (2) maintenance of the straining with an incremental relative tachycardia secondary to a progressive arterial pressure decrease (phase II); (3) release of straining with progression of the tachycardia to the maximum following an additional sudden dip in arterial pressure (phase III); (4) post-straining cessation of the tachycardia in variable time and onset of the progressive relative bradycardia in response to the rapid arterial pressure overshooting, which lasts several seconds until the complete recovery to the basal level (phase IV). The manoeuvres were considered effective when facial plethora, neck vein distension, and abdominal muscle contracture were observed. The chagasic and control groups performed a total of 103 and 144 valid Valsalva manoeuvres, respectively.

\subsection{Heart interval variation indices}

The lead II of the electrocardiogram for acquisition of the $\mathrm{R}-\mathrm{R}$ interval series was continuously recorded with a conventional electrocardiograph in the resting supine position at a paper speed of $25 \mathrm{~mm} / \mathrm{s}$ from $10 \mathrm{~s}$ before until around $90 \mathrm{~s}$ after the Valsalva manoeuvre into the recovery phase. The $\mathrm{R}-\mathrm{R}$ interval sequence was manually measured with an electrocardiographic precision ruler and compiled for electronic calculation of the different variation indices. As previously reported (Junqueira, 1990), the following indices were calculated from the different phases of the Valsalva manoeuvre, the last two being introduced in the previous study: (a) relative tachycardia (\%), defined as the percent difference between the progressively attained shortest $\mathrm{R}-\mathrm{R}$ interval during or immediately after the manoeuvre (maximum tachycardia - phase III) and the longest control R-R interval (the shortest $\mathrm{R}-\mathrm{R}$ minus control $\mathrm{R}-\mathrm{R} \times 100$ /control $\mathrm{R}-\mathrm{R}$ ); (b) relative bradycardia (\%), reported as the percent difference between the progressively attained longest $\mathrm{R}-\mathrm{R}$ interval after the manoeuvre (maximum bradycardia- phase IV) and the longest control $R-R$ interval (the longest $R-R$ minus control $\mathrm{R}-\mathrm{R} \times 100$ /control $\mathrm{R}-\mathrm{R}$ ); (c) Valsalva ratio (Levin, 1966), which is the ratio between the longest $R-R$ interval after the manoeuvre (maximum bradycardia - phase IV) and the shortest $\mathrm{R}-\mathrm{R}$ interval during or immediately after the manoeuvre (maximum tachycardia-phase III) (the longest $\mathrm{R}-\mathrm{R} /$ the shortest $\mathrm{R}-\mathrm{R}$ ); (d) time for the maximum $\mathrm{R}-\mathrm{R}$ interval variation or time for phases III-IV bradycardia (s), expressed as the time from maximum tachycardia in phase III (the shortest $\mathrm{R}-\mathrm{R}$ ) to the maximum bradycardia in phase IV (the longest $\mathrm{R}-\mathrm{R}$ ); (e) velocity of the maximum $\mathrm{R}$ $\mathrm{R}$ interval variation or velocity of phases III-IV bradycardia (or rate of the total bradycardia attained corrected by their run time) $(\% / s)$, defined as the ratio between the percent difference of maximum bradycardia in phase IV (the longest $R-R$ ) to the maximum tachycardia in phase III (the shortest $\mathrm{R}-\mathrm{R}$ ) and the time for attaining the change (the longest $\mathrm{R}-\mathrm{R}$ minus the shortest $\mathrm{R}-\mathrm{R} \times 100 /$ the shortest $\mathrm{R}-\mathrm{R} /$ time for the maximum variation of $\mathrm{R}-\mathrm{R}$ ). For each index of heart interval variation, an averaged value was derived from several Valsalva manoeuvres performed per individual, which was considered for the sample group. Fig. 1 depicts how the different indices were measured.

\subsection{Statistical analysis}

Variables were tested for normality before comparative analysis. The variables with normal distribution in both groups had their means \pm S.D. compared using the onetailed $t$-test, and those which were not normally distributed in one or in both groups had their medians compared employing the one-tailed Mann-Whitney test. Both tests were employed whenever indicated to preserve the power of each one. The significance level of difference was set at $5 \%$ $(p<0.05)$. According to the variables distribution, the Pearson's correlation coefficient $(r)$ or the Spearman's rank correlation coefficient $\left(r_{\mathrm{S}}\right)$ was obtained to evaluate the correlation between each heart interval variation index with the age and gender for the control group. Analysis and graphical design of the data employed the SigmaStat ${ }^{\circledR}$ (Jandel Scientific, USA, 1993) and the Prism ${ }^{\circledR}$ (GraphPad, USA, 1997) software packages, respectively.

\section{Results}

No significant $(p=0.39-0.71)$ correlation was found between the individual means of any heart interval variation indices and the respective age $\left(r=0.05-0.11\right.$ or $r_{\mathrm{S}}=0.08-$ $0.09)$, basal arterial pressure $(r=0.10)$, and control $\mathrm{R}-\mathrm{R}$ interval mean $(r=0.12)$ for each subject in the control group.

Table 1 summarizes the data for the chagasic and control groups and shows the results of comparison between both. The median (quartiles) of the relative bradycardia did not show significant difference ( $p=0.63)$ between the chagasic $(23.7 \% \mathrm{~ms} ; 9.7-29.7 \% \mathrm{~ms})$ and control $(22.7 \% \mathrm{~ms} ; 12.2-$ $32.6 \% \mathrm{~ms}$ ) groups, but the median (quartiles) of the relative tachycardia was smaller in chagasic $(31.7 \% \mathrm{~ms} ; 23.5-$ $35.7 \% \mathrm{~ms})$ than in control $(35 \% \mathrm{~ms} ; 30.3-40.3 \% \mathrm{~ms})$ group $(p=0.02)$. The comparison of the median (quartiles) Valsalva ratio between the groups showed a borderline $p$ value 
Table

Summary statistics of the basal R-R interval and the Valsalva manoeuvre-derived heart interval variation indices and comparison between 52 controls (C) and 36 Chagas' indeterminate disease (CHG) subjects

\begin{tabular}{|c|c|c|c|c|c|c|c|c|c|c|c|c|}
\hline & \multicolumn{2}{|c|}{ Basal $\mathrm{R}-\mathrm{R}$ interval (ms) } & \multicolumn{2}{|c|}{$\begin{array}{l}\text { Relative tachycardia } \\
(-\Delta \% \mathrm{~ms})\end{array}$} & \multicolumn{2}{|c|}{$\begin{array}{l}\text { Relative bradycardia } \\
(\Delta \% \mathrm{~ms})\end{array}$} & \multicolumn{2}{|c|}{ Valsalva ratio } & \multicolumn{2}{|c|}{$\begin{array}{l}\text { Time for phases III-IV } \\
\text { bradycardia (s) }\end{array}$} & \multicolumn{2}{|c|}{$\begin{array}{l}\text { Velocity of phases III-IV } \\
\text { bradycardia }(\Delta \% / \mathrm{s})\end{array}$} \\
\hline & $\mathrm{C}$ & CHG & $\mathrm{C}$ & CHG & $\mathrm{C}$ & CHG & $\mathrm{C}$ & CHG & $\mathrm{C}$ & CHG & $\mathrm{C}$ & CHG \\
\hline Distribution of variable & normal & normal & normal & normal & normal & normal & non-normal & normal & non-normal & normal & non-normal & non-normal \\
\hline Mean & 922 & 908 & 35 & 30.8 & 23.7 & 22.1 & 1.93 & 1.82 & 11.1 & 15.7 & 10.3 & 6.4 \\
\hline S.D. & 155 & 104 & 7.8 & 8.8 & 15.6 & 13.9 & 0.33 & 0.40 & 5.2 & 6.7 & 5.1 & 3.8 \\
\hline Median & 891 & 901 & 35 & 31.7 & 22.7 & 23.7 & 1.90 & 1.78 & 10.3 & 14.2 & 8.9 & 5.1 \\
\hline Lower-upper quartiles & $823-1003$ & $840-979$ & $30.3-40.3$ & $23.5-35.7$ & $12.2-32.6$ & $9.7-29.7$ & $1.76-2.12$ & $1.47-2.07$ & $7.1-13.6$ & $11.3-18.6$ & $7-13.6$ & $3.7-8.6$ \\
\hline Lower-upper extreme values & $593-1306$ & $700-1167$ & $14.6-55$ & $14.6-50.6$ & -1.8 to 68.6 & $0.7-51.1$ & $1.33-2.71$ & $1.27-2.94$ & $3-24.7$ & $5.7-36.5$ & $2.4-26.9$ & $0.7-16.5$ \\
\hline$p$ Value & 0.65 & & 0.02 & & 0.63 & & 0.08 & & $<0.001$ & & $<0.001$ & \\
\hline Statistic test & $t$-test & & $t$-test & & $t$-test & & Mann-Whi & ey test & Mann-Whit & $y$ test & Mann-Whi & test \\
\hline
\end{tabular}

See Subjects and methods for the definition of the Valsalva manoeuvre-derived heart interval variation indices. 
$(p=0.08)$, which indicates a tendency for the chagasic $(1.78 ; 1.47-2.07)$ to present a smaller value than the control group $(1.90 ; 1.76-2.12)$.

The time-dependent indices of the phases III-IV bradycardia showed values statistically different for the two groups. The median (quartiles) time for this heart rate response was greater $(p<0.001)$ for the chagasics $(14.2$; $11.3-18.6 \mathrm{~s})$ than for the controls $(10.3 ; 7.1-13.6 \mathrm{~s})$, and the median (quartiles) velocity was smaller $(p<0.001)$ in the chagasic $(5.1 \% / \mathrm{s} ; 3.7-8.6 \% / \mathrm{s})$ than in the control group $(8.9 \% / \mathrm{s} ; 7-13.6 \% / \mathrm{s})$.

Fig. 1 illustrates typical normal and abnormal heart interval changes in representative Valsalva manoeuvres performed by one control individual and one chagasic patient, respectively.

In $34(94.4 \%)$ chagasics, it was observed at least one index of $\mathrm{R}-\mathrm{R}$ interval variation below the lower (25th percentile) or above the upper quartile (75th percentile) of the control group. Five $(13.9 \%)$ of these individuals showed combinably all the indices beyond the control quartiles, that is, the relative tachycardia and bradycardia, Valsalva ratio and velocity of phases III-IV bradycardia showing values below the lower quartile, and the time for this bradycardia above the upper quartile. In $29(80.5 \%)$ chagasics, one or more indices were outside the control interquartile range. At least one exclusively depressed index of rate- and/or time-dependent heart interval responses beyond the 25 th or 75 th percentile was observed in $21(58.3 \%)$ out of 36 chagasics, and at least one exclusively enhanced index was encountered in three $(8.3 \%)$. In $10(27.8 \%)$ individuals, it was observed at least one depressed and one enhanced index outside the control interquartile range. Only two $(5.6 \%)$ chagasics showed each index within this range. Table 2 summarizes the
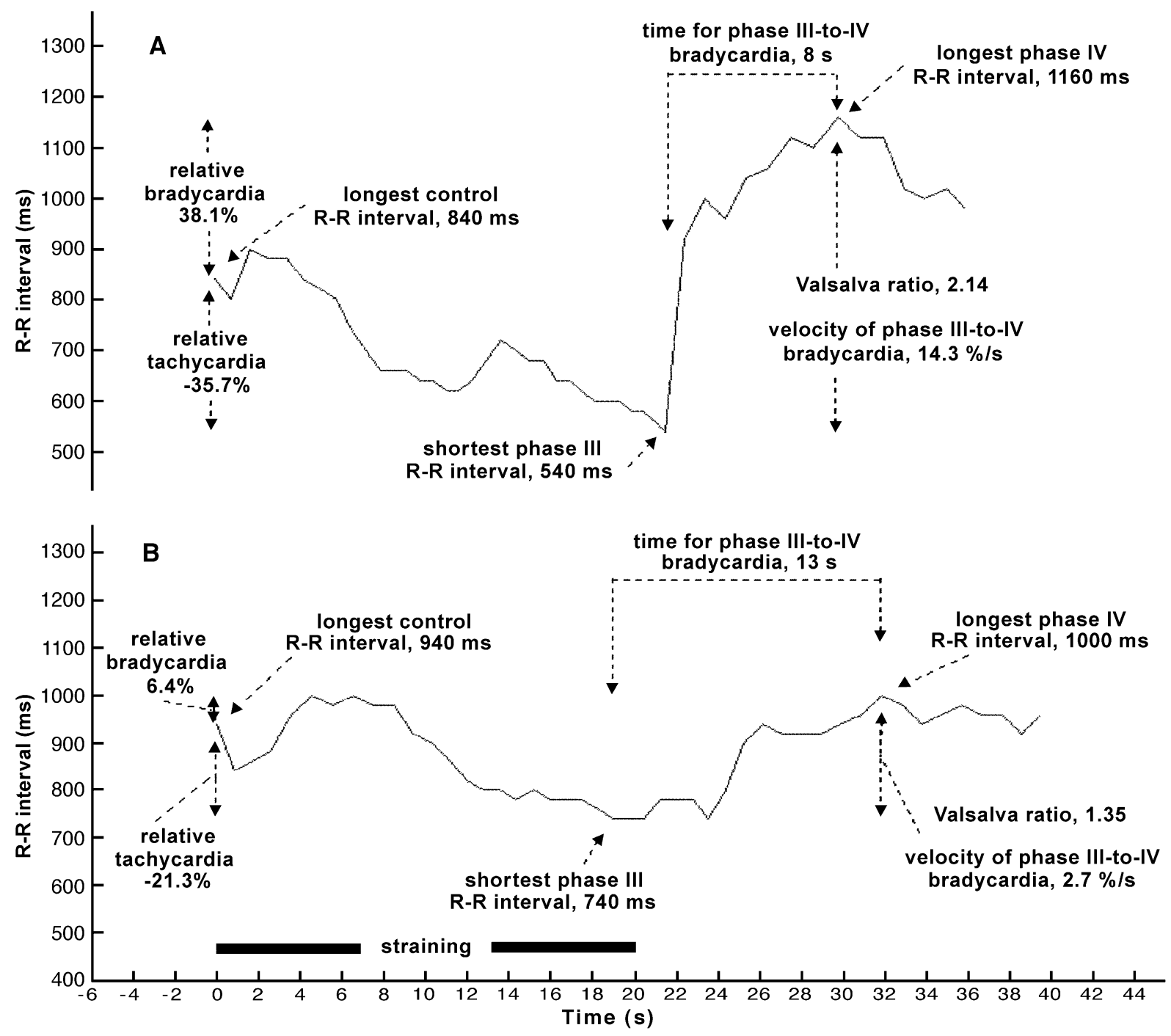

Fig. 1. Typical beat-to-beat heart interval changes in the four different phases of a representative Valsalva manoeuvre from one control healthy male subject aged 30 years (A) and one female patient aged 35 years with apparent Chagas' indeterminate disease (B). The control and the shortest and longest R-R interval besides the indication of how the rate- and time-dependent indices of heart interval changes were measured are depicted. It may appreciate the blunted ratedependent and delayed time-dependent heart interval changes observed in the majority of the chagasic patients. 
Table 2

Proportion of Chagas' indeterminate disease subjects that showed Valsalva manoeuvre-derived heart interval variation indices values inside or beyond the interquartile range (25th-75th percentiles) observed for the control group

\begin{tabular}{llr}
\hline & $\begin{array}{l}\text { Number of } \\
\text { chagasics }\end{array}$ & $\%$ \\
\hline $\begin{array}{l}\text { All indices inside the control } \\
\text { interquartile range }\end{array}$ & 2 & 5.6 \\
$\begin{array}{l}\text { All indices beyond the control } \\
\text { interquartile range (reduced values) }\end{array}$ & 5 & 13.9 \\
$\begin{array}{l}\text { One or more indices beyond the control } \\
\text { interquartile range (reduced values) }\end{array}$ & 16 & 44.4 \\
$\begin{array}{l}\text { All indices beyond the control } \\
\text { interquartile range (increased values) }\end{array}$ & 0 & 0 \\
$\begin{array}{l}\text { One or more indices beyond the control } \\
\text { interquartile range (increased values) }\end{array}$ & 3 & 8.3 \\
$\begin{array}{l}\text { More than one index beyond the control } \\
\text { interquartile range (some reduced and } \\
\text { others increased values) }\end{array}$ & 10 & 27.8 \\
\begin{tabular}{l} 
Total number of chagasic subjects \\
\hline
\end{tabular} & 36 & 100 \\
\hline
\end{tabular}

proportion of chagasic subjects with the different-values patterns of heart interval indices.

Fig. 2 illustrates the statistic parameters of heart interval variation indices for the chagasic in comparison with control group of subjects.

\section{Discussion}

Although the incidence of new cases of Chagas' disease has fallen close to zero after the successful control of the vector transmission (Schofield and Dias, 1998), it remains a large group of chronically infected individuals, the majority in the indeterminate form of the disease, which is emerging as one of the great focuses of interest (Oliveira et al., 1986; Dias, 1989; Ribeiro and Rocha, 1998; Macêdo, 1999). This form ever shows intriguing pathological, functional, clinical, and epidemiological aspects, incorporating several unsolved or controversial questions, one of which is concerned with the cardiac sinus node autonomic modulation. In this regard, the question is whether there is any detectable cardiac autonomic disturbance in the Chagas' indeterminate disease and what is its pathophysiological and clinical significance.

The Valsalva manoeuvre is one of the most widely used and informative procedures for the study of the autonomic nervous system modulation on the sinus node activity (Ewing, 1978; Eckberg, 1980; Espi et al., 1986; Nishimura and Tajik, 1986). The heart rate responses to the Valsalva manoeuvre are the result of reflex mechanisms predominantly baroreceptor in origin, which involve the parasympathetic autonomic nervous system with doubtful
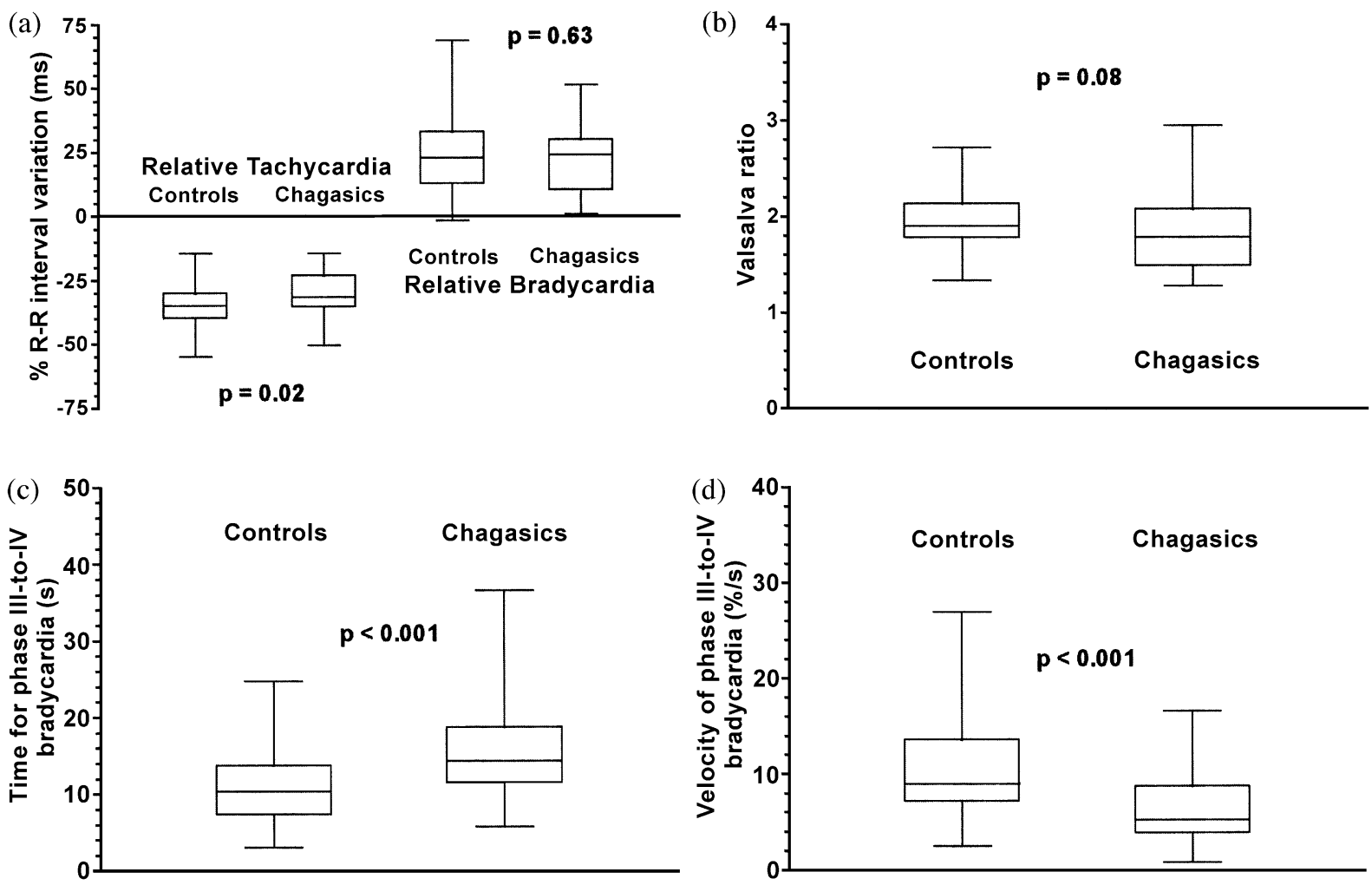

Fig. 2. Comparison of the Valsalva manoeuvre-associated heart interval variation indices between 52 healthy controls and 36 Chagas' indeterminate disease subjects. For each group are depicted the median, interquartile range and extreme values for: (a) the percent $\mathrm{R}-\mathrm{R}$ interval decrement (phase III- tachycardia) and increment (phase IV_-bradycardia) in relation to the basal values before the manoeuvre; (b) Valsalva ratio; (c) time for the heart interval variation from the maximum tachycardia attained in phase III to the maximum bradycardia in phase IV (phases III-IV bradycardia); (d) velocity of this maximum tachycardiabradycardia heart interval variation. The chagasic and control groups were compared by the $t$-test or Mann-Whitney test according to the normality or not of the variables distribution. 
involvement of the sympathetic one (Ewing, 1978; Eckberg, 1980). It has been claimed that the bradycardia following the manoeuvre is entirely parasympathetic. The mechanism of the tachycardia during the manoeuvre remains controversial, some workers suggesting exclusive enhancement of sympathetic activity and others suggesting depression of parasympathetic outflow; also, both parasympathetic withdrawal and increased sympathetic outflow have been suggested (Bennett et al., 1976; Eckberg, 1980).

The quantification of heart interval variations during the Valsalva manoeuvre has been used as a sensitive and very simple method for characterizing cardiac parasympathetic activity in healthy subjects and in patients with diabetes (Bennett et al., 1976; Baldwa and Ewing, 1977; Ewing, 1978; Kruter et al., 1982; Ewing et al., 1985), coronary heart disease (Tristani et al., 1977), hypertension (Trimarco et al., 1983), and renal failure (Ewing and Winney, 1975) which showed reduced variations in the $\mathrm{R}-\mathrm{R}$ interval as a result of cardiac autonomic dysfunction, as presently observed in chagasic subjects.

The manoeuvre may be easily performed by almost anyone after instruction and training and it is usually safe and innocuous. A critical concern is the comparability of the Valsalva manoeuvre procedure in different groups of individuals, since the $\mathrm{R}-\mathrm{R}$ interval changes are not quantified in relation to the documented blood pressure alterations. According to Eckberg (1980), difficulties can arise in interpreting $\mathrm{R}-\mathrm{R}$ interval or heart rate responses in the Valsalva manoeuvre when some elementary conditions of equality of the procedure are not met for comparison with control subjects. In this respect, we can state that the stimuli associated with the manoeuvres performed were comparable in both groups studied, that is, the depth of inspiration before straining, the intensity and duration of straining, and the magnitude of the intra-oral pressure were all well controlled. Moreover, a large number of individuals and manoeuvres were presently analysed. It is unlikely that the functional alterations observed were due to factors other than the variable disturbed cardiac autonomic modulation.

In the present work, we observed that the chagasic group showed discrete to moderate cardiac autonomic dysfunction characterized by depressed tachycardia response and delayed time-dependent bradycardia responsiveness implicated in the phases II, III, and IV of the Valsalva manoeuvre. Individually, chagasic subjects presented distinctive patterns of cardiac autonomic functional status, which includes depression, and less frequent enhancement or normality of the heart interval responses. Thus, the cardiac autonomic impairment previously detected in Chagas' heart disease patients by complex and invasive or simple noninvasive tests (Amorim et al., 1982; Gallo et al., 1987; Marin-Neto et al., 1980, 1998; Junqueira, 1990; Guzzetti et al., 1991; Dávila et al., 1998) was also presently noted in chagasic patients with the apparent indeterminate form. This observation reinforces previous findings of suggestive cardiac dysautonomia in these chagasics based on different method- ologies of cardiac autonomic evaluation (Macêdo et al., 1974; Iosa et al., 1980; Palmero et al., 1980; Guzzetti et al., 1991; Ribeiro et al., 2001). The prolonged time and the reduced velocity of heart interval change from the maximum tachycardia to maximum bradycardia post-manoeuvre may be consequent to delayed inhibition or reversion of the ongoing sympathetic hyperactivity in phases II and III with retarded suppression of tachycardia in phase III and installation of bradycardia in phase IV, or to delayed stimulation of the attenuated or normal parasympathetic activity in phases II and III with slow installation of bradycardia in phase IV.

The indices of heart interval variations showed different sensitivities in detecting cardiac autonomic dysfunction. The most sensitive appeared to be the time-related indices, velocity, and time of phases III-IV bradycardia. The relative bradycardia frequently employed to characterize cardiac autonomic function by means of the Valsalva manoeuvre proved to be a very poor index in view of their similarity between the groups and great variability of the individual mean values. As to the Valsalva ratio, the mean \pm S.D. value of $1.93 \pm 0.33$ presently observed in the control group is identical to that verified in our previous work (Junqueira, 1990 ) and close to the $1.83 \pm 0.37$ value reported by Baldwa and Ewing (1977) and the $1.86 \pm 0.35$ value reported by Kruter et al. (1982), but higher than the $1.69 \pm 0.31(20-34$ years) and $1.78 \pm 0.41$ (35-49 years) values reported by Espi et al. (1986) for healthy subjects. Based on a large number of individuals, Levin (1966) indicated 1.50 as the lower limit of normality, a slightly greater value than the lower extreme of 1.33 observed in the present study. Low et al. (1975) also considered ratio indices above 1.50 to be normal. The relative tachycardia and the time and velocity of phases III-IV bradycardia in the present control manoeuvres were also similar to the values previously observed by us in healthy subjects (Junqueira, 1990).

Considering the individual indices values for the chagasic subjects in relation to the distribution in the control group, only $13.9 \%$ of chagasics showed all indices behind the control interquartile range, suggesting more severe depressed cardiac autonomic modulation, while $80.5 \%$ exhibited one or more indices outside this range, indicating a borderline or a discrete to moderate autonomic depression or exacerbation. All the indices were within the normal interquartile range for the remaining $5.6 \%$ chagasics, signifying that only these few subjects showed no tendency for or established autonomic impairment. It could be verified for the first time that some chagasics $(8.3 \%)$ presented one or more indices reflecting enhancement of the cardiac autonomic activity, which may signify the possibility of the existence of a stage of functional hypersensitivity in the natural course of the chagasic cardiac autonomic dysfunction, in the context of Cannon's denervated structures law. In fact, the indeterminate form of Chagas' disease may represent an initial or intermediary pathological stage in the natural evolution of the overt Chagas' heart disease. 
The disturbance observed in the chagasics presently examined was certainly not dependent of their greater ages since no correlation was found between age and heart interval indices for the control group. It is very likely that the alterations in the Valsalva indices were exclusively or predominantly due to primary disturbed efferent parasympathetic influence on the heart. Some degree of impairment of sympathetic activity cannot be fully excluded, particularly considering the definite reduction in relative tachycardia and the tendency for reduction of Valsalva ratio. In fact, according to a critical view, complex interactions occur between the parasympathetic and sympathetic divisions at the central nervous system and at the heart level, and the affirmation of exclusively disturbed function of one or other autonomic division is imprecise and may be misleading (Levy, 1971).

The pathogenesis and the pathophysiological and clinical significance of the disturbed cardiac autonomic modulation in indeterminate Chagas' disease can only be conjectured. The more probable pathogenetic mechanism is the primary direct chronic inflammatory or autoimmunological damage of ganglia and/or neuronal fibres (Lopes and Tafuri, 1983; Oliveira, 1985), as classically accepted on the basis of human and experimental animal studies (Junqueira et al., 1992; Marin-Neto, 1998). The possibility that in chagasics with the indeterminate form of disease, the autonomic disturbance is only due to neuroganglionic inflammation, is reinforced by the observation in the experimental rat model of $T$. cruzi infection developed in our laboratory that the exclusive presence of ganglionic and/or neuronal inflammation without neuroganglionic depopulation was sufficient to cause depression of the phenylephrine-induced baroreflex bradycardia (Chapadeiro et al., 1991). It is important to consider that this animal model imitates particularly the indeterminate form of human Chagas' disease, considering the discrete and focal nature of the underlying lesions (Junqueira et al., 1992). Another pathogenetic mechanism to explain the cardiac dysautonomia is the binding of circulating autoantibodies to beta-adrenergic and muscarinic cholinergic receptors of heart, triggering alterations in neurotransmission or in intracellular signal transduction resulting in progressive autonomic denervation (SterinBorda and Borda, 2000). It is possible that one or other mechanism, exclusively, may be responsible for the autonomic disturbance or may coexist in variable degree in different subjects and in distinctive moments of the evolution of the disease. An alternative pathogenetic view considers the cardiac autonomic impairment secondary to the myocardial involvement or ventricular mechanical dysfunction (Dávila et al., 1998), but this is not convincing.

Autonomic dysfunction may be determinant or the contributor factor in the pathogenesis of electrophysiological and mechanical disturbances of heart, such as arrhythmias (Junqueira, 1991; Baroldi et al., 1997) and chronic progression of myocardial contractile deficiency, alterations in left ventricular dimensional relations, wall motion abnormalities and contractile dynamics, and morphological mod- ifications and apical aneurysm, all of which were proved to occur in the indeterminate Chagas' disease (Maciel et al., 1995; Ribeiro and Rocha, 1998; Simões et al., 2000). The autonomic disturbance may also impair mechanisms of cardiovascular adaptation, preventing the affected subject from adequately performing physical and physiological activities dependent on the normal cardiac autonomic modulation. Less probably, cardiac autonomic dysfunction in Chagas' disease may only be a phenomenon isolated or concurrent to other disturbances, without any pathophysiological or clinical significance.

One possible limitation of our study concerns the lack of extensive validation of the new Valsalva manoeuvre-associated indices of heart interval changes used, although their good reliability (Junqueira, 1990; Marin-Neto et al., 1998), the strong confidence that the present findings in Chagas' disease subjects examined are really true considering the pertinence of the results, and the employment of some such indices by others proving its validity (Marin-Neto et al., 1998). Moreover, ongoing analysis in our laboratory has shown significant and good correlation between the indices presently used and the baroreflex sensitivity measured by the phenylephrine injection method (unpublished data).

In conclusion, subtle variable and predominant depression of cardiac autonomic modulation were detected in Chagas' disease subjects with apparent indeterminate form, on the basis of very simple rate- and time-dependent indices of bradycardia and tachycardia responses in the Valsalva manoeuvre. Enhanced autonomic activity was, for the first time, identified in some chagasics. The most probable explanations for the autonomic abnormalities are the chronic inflammatory or autoimmunological damage of the cardiac intrinsic innervation and/or autoantibodies-induced derangements in cardiac neurotransmitter receptors.

\section{Acknowledgements}

The authors acknowledge the technical assistance of Mrs. Maria da Graça Sousa and Mr. João Ronaldo de Andrade Rocha, and the collaboration of the medical students Cleverson Teixeira Soares and Délio José Braz Jr. This work was partially supported by grants from $\mathrm{CNPq}$ (40.3748/82, 30.1705/85, 40.7647/85, 82.0323/86).

\section{References}

Amorim, D.S., Manço, J.C. , Gallo Jr., L., Marin-Neto, J.A. 1982. Chagas' heart disease as an experimental model for studies of cardiac autonomic function in man. Mayo Clin. Proc. 57, 48-60.

Andrade, Z., 1984. The canine model of Chagas' disease. Mem. Inst. Oswaldo Cruz 79, 77-83 (suppl.).

Baldwa, V.S., Ewing, D.J., 1977. Heart rate response to Valsalva manoeuvre. Reproducibility in normals, and relation to variation in resting heart rate in diabetics. Br. Heart J. 39, 641-644.

Baroldi, G., Oliveira, S.J., Silver, M.D., 1997. Sudden and unexpected death in clinically silent Chagas' disease. A hypothesis. Int. J. Cardiol. $58,263-268$. 
Bennett, T., Hosking, D.J., Hampton, J.R., 1976. Baroreflex sensitivity and responses to the Valsalva manoeuvre in subjects with diabetes mellitus. J. Neurol. Neurosurg. Psychiatry 39, 178-183.

Chapadeiro, E., Florêncio, R.F.C., Afonso, P.C., Beraldo, P.S.S., Jesus, P.C., Junqueira Jr., L.F., 1991. Neuronal counting and parasympathetic dysfunction in the hearts of chronically Trypanosoma cruzi-infected rats. Rev. Inst. Med. Trop. São Paulo 33, 337-341.

Chapadeiro, E., Silva, E.L., Silva, A.C.M., Fernandes, P., Ramirez, L.E., 1999. Despopulação neuronal cardíaca em hamsters (Mesocricetus auratus) cronicamente infectados com o Trypanosoma cruzi. Rev. Soc. Bras. Med. Trop. 32, 35-39.

Dávila, D.F., Inglessis, G., Dávila, C.A.M., 1998. Chagas' heart disease and autonomic nervous system. Int. J. Cardiol. 66, 123-127.

Dias, J.C.P., 1989. The indeterminate form of human chronic Chagas' disease. A clinical epidemiological review. Rev. Soc. Bras. Med. Trop. 22, $147-156$.

Eckberg, D.L., 1980. Parasympathetic cardiovascular control in human disease: a critical review of methods and results. Am. J. Physiol. 239, H581-H593.

Espi, F., Canteras, M., Benages, A., Carmena, R., 1986. Evaluación de la maniobra de Valsalva y del ejercicio muscular isometrico en los individuos normales. Rev. Esp. Cardiol. 39, 213-219.

Ewing, D.J., 1978. Cardiovascular reflexes and autonomic neuropathy. Clin. Sci. Mol. Med. 55, 321-327.

Ewing, D.J., Winney, R., 1975. Autonomic function in patients with chronic renal failure on intermittent hemodialysis. Nephron 15, 424-429.

Ewing, D.J., Martyn, C.N., Young, R.J., Clarke, B.F., 1985. The value of cardiovascular autonomic function tests: 10 years experience in diabetes. Diabetes Care 8, 491-498.

Gallo Jr., L., Morelo Filho, J., Maciel, B.C., Marin-Neto, J.A., Martins, L.E.B., Lima Filho, E.C. 1987. Functional evaluation of sympathetic and parasympathetic system in Chagas' disease using dynamic exercise. Cardiovasc. Res. 21, 922-927.

Guzzetti, S., Iosa, D., Pecis, M., Bonura, L., Prosdocimi, M., Malliani, A., 1991. Impaired heart rate variability in patients with chronic Chagas' disease. Am. Heart J. 121, 1727-1734.

Iosa, D.J., Caeiro, T.F., Palmero, H.A., 1980. Abnormal hyperventilation test in chronic Chagas' disease. J. Auton. Nerv. Syst. 2, 87-92.

Junqueira Jr., L.F. 1990. Ambulatory assessment of cardiac autonomic function in Chagas' heart disease patients based on indexes of $R-R$ interval variation in the Valsalva maneuver. Braz. J. Med. Biol. Res. 23, $1091-1102$.

Junqueira Jr., L.F., 1991. Sobre o possível papel da disfunção autonômica cardíaca na morte súbita associada a doença de Chagas. Arq. Bras. Cardiol. 56, 429-434.

Junqueira Jr., L.F., Gallo Jr., L., Manço, J.C., Marin-Neto, J.A., Amorim, D.S., 1985. Subtle cardiac autonomic impairment in Chagas' disease detected by baroreflex sensitivity testing. Braz. J. Med. Biol. Res. 18, $171-178$.

Junqueira Jr., L.F., Beraldo, P.S.S., Chapadeiro, E., Jesus, P.C. 1992. Cardiac autonomic dysfunction and neuroganglionitis in a rat model of chronic Chagas' disease. Cardiovasc. Res. 26, 324-329.

Kruter, R.H.E., Eizirik, D.L., Gross, J.L., 1982. Relationship of the Valsalva ratio to autonomic neuropathy and other complications of diabetes mellitus. Braz. J. Med. Biol. Res. 15, 35-41.

Levin, A.B., 1966. A simple test of cardiac function based upon the heart rate changes induced by the Valsalva maneuver. Am. J. Cardiol. 18, 90-99.

Levy, M.N., 1971. Sympathetic-parasympathetic interactions in the heart. Circ. Res. 29, 437-445.

Lopes, E.R., Tafuri, W.L., 1983. Involvement of the autonomic nervous system in Chagas' heart disease. Rev. Soc. Bras. Med. Trop. 16, $206-$ 212.

Low, P.A., Walsh, J.C., Huang, C.Y., McLeod, J.G., 1975. The sympathetic nervous system in diabetic neuropathy. A clinical and pathological study. Brain 98, 341-356.
Macêdo, V., 1999. Indeterminate form of Chagas' disease. Mem. Inst. Oswaldo Cruz 94 (suppl. I), 311-316.

Macêdo, V.O., Prata, A.R., Silva, A., 1974. Teste da pilocarpina na forma indeterminada da doença de Chagas. Rev. Goiana Med. 20, 191-199.

Machado, C.R., Caliari, M.V., de Lana, M., Tafuri, W.L., 1998. Heart autonomic innervation during the acute phase of experimental American trypanosomiasis in the dog. Am. J. Trop. Med. Hyg. 59, 492-496.

Maciel, B.C., Almeida Filho, O.C., Schmidt, A., Marin-Neto, J.A., 1995. Ventricular function in Chagas' heart disease. Rev. Paul. Med. 113, $814-820$.

Manço, J.C., Gallo Jr., L., Godoy, R.A., Fernandes, R.G., Amorim, D.S. 1969. Degeneration of the cardiac nerves in Chagas' disease. Further studies. Circulation 40, 879-885.

Marin-Neto, J.A., 1998. Cardiac dysautonomia and pathogenesis of Chagas' heart disease. Int. J. Cardiol. 66, 129-131.

Marin-Neto, J.A., Gallo Jr., L., Manço, J.C., Rassi, A., Amorim, D.S. 1980. Mechanisms of tachycardia on standing: studies in normal individuals and in chronic Chagas' heart patients. Cardiovasc. Res. 14, 541-550.

Marin-Neto, J.A., Bromberg-Marin, G., Pazin-Filho, A., Simões, M.V., Maciel, B.C., 1998. Cardiac autonomic impairment and early myocardial damage involving the right ventricle are independent phenomena in Chagas' disease. Int. J. Cardiol. 65, 261-269.

Nishimura, R.A., Tajik, A.J., 1986. The Valsalva maneuver and response revisited. Mayo Clin. Proc. 61, 211-217.

Oliveira, J.S.M., 1985. A natural human model of intrinsic heart nervous system denervation: Chagas' cardiopathy. Am. Heart J. 110, 1092-1098.

Oliveira Jr., W., Salazar, L.F., Malta, J., Assi, N. 1986. Análise crítica da forma indeterminada da doença de Chagas. Arq. Bras. Cardiol. 47, $283-288$.

Palmero, H.A., Caeiro, T.F., Iosa, D.J., 1980. Distinctive abnormal response to tilting test in chronic Chagas' disease. Klin. Wochenschr. 58, 13071311.

Ribeiro, A.L.P., Rocha, M.O.C., 1998. Forma indeterminada da doença de Chagas: considerações acerca do diagnóstico e do prognóstico. Rev. Soc. Bras. Med. Trop. 31, 301-314.

Ribeiro, A.L.P., Moraes, R.S., Ribeiro, J.P., Ferlin, E.L., Torres, R.M., Oliveira, E., Rocha, M.O.C., 2001. Parasympathetic dysautonomia precedes left ventricular systolic dysfunction in Chagas' disease. Am. Heart J. 141, 260-265.

Schofield, C.J., Dias, J.C.P., 1998. The Southern Cone Initiative against Chagas' disease. Adv. Parasitol. 42, 1-27.

Simões, M.V., Pintya, A.O., Bromberg-Marin, G., Sarabanda, A.V., Antloga, C.M., Pazin-Filho, A., Maciel, B.C., Marin-Neto, J.A., 2000. Relation of regional sympathetic denervation and myocardial perfusion disturbance to wall motion impairment in Chagas' cardiomyopathy. Am. J. Cardiol. 86, 975-981.

Souza, M.M., Andrade, S.G., Barbosa Jr., A.A., Santos, R.T.M., Alves, V.A.F., Andrade, Z.A. 1996. Trypanosoma cruzi strains and autonomic nervous system pathology in experimental Chagas' disease. Mem. Inst. Oswaldo Cruz 91, 217-224.

Sterin-Borda, L., Borda, E., 2000. Role of neurotransmitter autoantibodies in the pathogenesis of chagasic peripheral dysautonomia. Ann. N. Y. Acad. Sci. 917, 273-280.

Tafuri, W.L., 1970. Pathogenesis of lesions of the autonomic nervous system of the mouse in experimental acute Chagas' disease. Am. J. Trop. Med. Hyg. 19, 405-417.

Trimarco, B., Volpe, M., Ricciardelli, B., Vigorito, C., De Luca, N., Sacca, V., Condorelli, M., 1983. Valsalva maneuver in the assessment of baroreflex responsiveness in borderline hypertensives. Cardiology 70, 6-14.

Tristani, F.E., Kamper, D.G., McDermott, D.J., Peters, B.J., Smith, J.J., 1977. Alterations of postural and Valsalva responses in coronary heart disease. Am. J. Physiol. 233, H694-H699.

WHO, 1991. Control of Chagas' diseaseWHO Technical Report Series, vol. 811. World Health Organization, Geneva. 